\title{
Assessment of the effects of skin microneedling as adjuvant therapy for facial melasma: a pilot study
}

\author{
Emerson V. A. Lima', Mariana Modesto D. A. Lima ${ }^{1}$, Mauricio Pedreira Paixão² and Hélio Amante Miot ${ }^{3,4^{*}}$
}

\begin{abstract}
Background: Melasma is a common chronic and relapsing acquired dyschromia. Skin microneedling was reported resulting sustained long-term improvement of recalcitrant melasma, however, the exact mechanism that promotes this skin lightening is not known. This study aimed to investigate clinical and histologic alterations promoted by skin microneedling in facial melasma.
\end{abstract}

Methods: Open pilot trial including six women with facial refractory melasma submitted to two sessions of microneedling $(1.5 \mathrm{~mm})$ each 30 days followed by daily triple combination and broad-spectrum sunscreen. Comparison of pretreatment (T0) and 15 days after last microneedling procedure (T45) was made by standardized pictures, skin colorimetry, MASI, MELASQoL and histological parameters (haematoxylin-eosin, picrosirius-red, periodic acid Schiff and Fontana-Masson staining).

Results: The age of the subjects varied from 34 to 46 years-old, the phototypes were III and IV (Fitzpatrick), and age of melasma onset was 20 to 38 years. Improvement of melasma was perceived in all subjects. There was a significant reduction of MASI score $(-70 \%)$, MELASQoL $(-55 \%)$ and increase in $L^{*}(+13 \%)$ colorimetric value $(p<0.03)$. All cases evidenced epithelium thickening, decrease in melanin pigmentation and densification of upper dermis collagen ( $p=0.03$ ). Patients were followed by 6 months under broad-spectrum sunscreen and triple combination without relapse.

Conclusion: In addition to classic treatment (broad-spectrum sunscreen and triple combination), skin microneedling promoted clinical and histological improvement of refractory facial melasma.

Keywords: Melasma, Treatment, Microneedling, Quality of life, Masi

\section{Background}

Melasma is a chronic and relapsing acquired dyschromia due to an increased epidermal-melanin unit activity that affects sun-exposed areas mainly in women throughout the reproductive years $[1,2]$.

Due to its high prevalence, the involvement of visible photoexposed areas - such as the face, in patients at a competitive age, and the relative resistance to treatment, melasma inflicts major impact on quality of life [3-5].

\footnotetext{
* Correspondence: heliomiot@gmail.com

${ }^{3}$ Unesp Medical School, Botucatu, SP, Brazil

${ }^{4}$ Departamento de Dermatologia, SN, Campus da Unesp, Botucatu, SP 18618-000, Brazil

Full list of author information is available at the end of the article
}

Its pathogenesis is not fully understood, nevertheless there is evidence that melanogenesis in melasma differ from tanning and post-inflammatory hyperpigmentation as well as there is an involvement of the whole epidermal melanin unit in the process (not just hypertrophic melanocytes), mastocytes, fibroblast and endothelium derived cytokines, as well as there are upper dermal abnormalities different from other acquired pigmentary disorders [6-8].

Skin microneedling, or percutaneous collagen induction by needles, is a minimally invasive procedure that uses short fine needles to puncture the skin and stimulates fibroblast proliferation, release of growth factors and collagen production [9-11]. Long-term improvement of recalcitrant melasma after microneedling was 


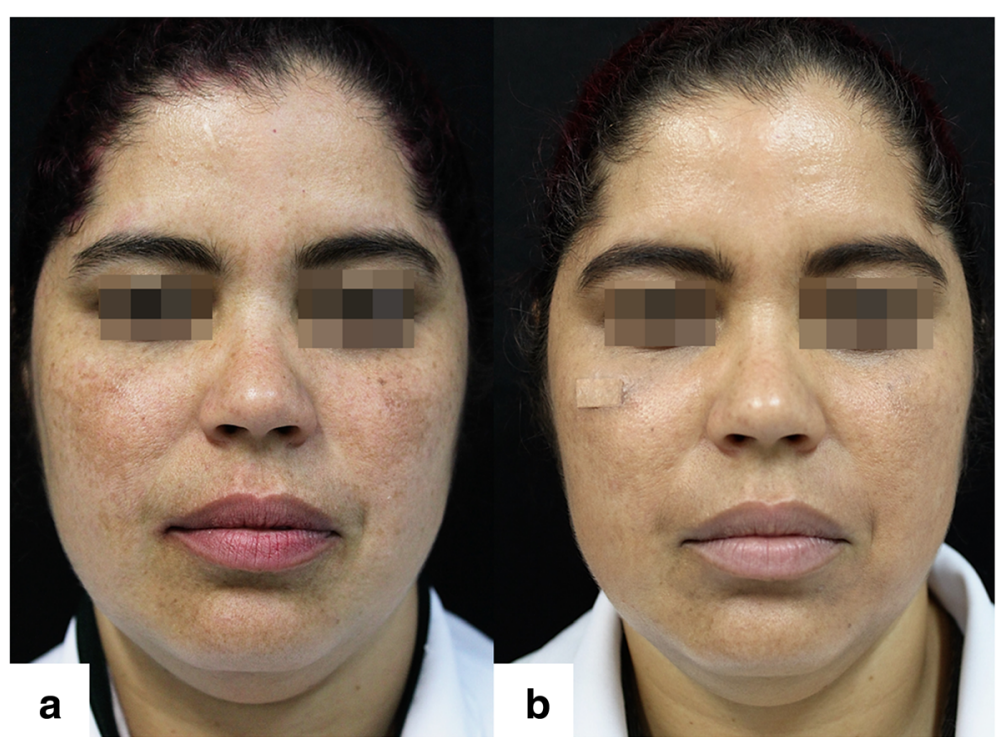

Fig. 1 Facial melasma: a Pre-treatment (T0). b Post-treatment after two sessions of microneedling, triple combination, and broad-spectrum sunscreen (T45)

reported in one case series, however, the exact mechanism that promotes skin lightening is not known $[12,13]$.

This study has investigated clinical and histologic alterations promoted by skin microneedling in facial melasma.

\section{Methods}

We performed an open pilot trial including women with facial refractory facial melasma, without specific treatment besides sunscreen for the last 30 days.
Refractory melasma was considered those with more than 5 years of evolution and relapsing to more than three attempting to treatment, including triple combination (hydroquinone, fluocinolone and tretinoin).

After consent, they were submitted to two sessions of microneedling (Dr. Roller ${ }^{\mathrm{Tm}}, 1.5 \mathrm{~mm}$ ) each 30 days (T0 and T30), followed (at the next day) by daily triple combination (Tri-Luma, Galderma) application and broadspectrum sunscreen (Anthelios Airlicium SPF $70 \mathrm{com}$ cor, La Roche Posay), according to Lima protocol [13].

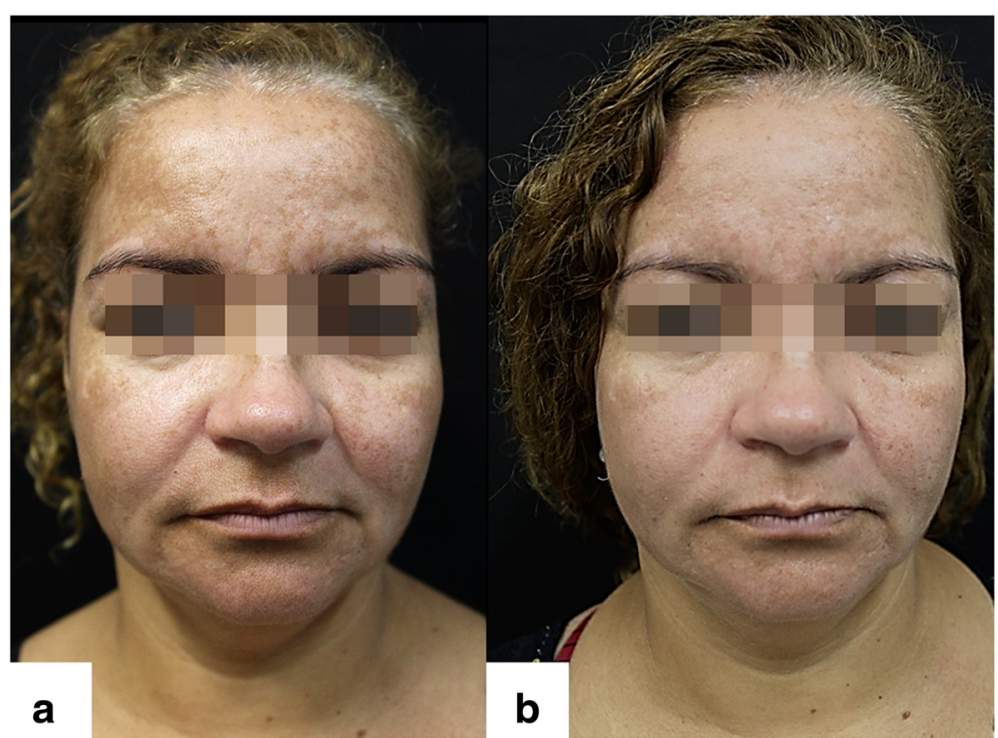

Fig. 2 Facial melasma: a Pre-treatment (TO). b Post-treatment after two sessions of microneedling, triple combination, and broad-spectrum sunscreen (T45) 
Table 1 Clinical, quality of life and colorimetric measures of melasma before and after two sessions of microneedling $(n=6)$

\begin{tabular}{llll}
\hline & Pre-treatment (T0) & Post-treatment (T45) & $p$-value \\
\hline MASI & $37.1(8.2)$ & $11.0(2.9)$ & 0.001 \\
Colorimetry & & & \\
L $^{*}$ & $43.5(3.4)$ & $49.2(2.5)$ & 0.015 \\
$a^{*}$ & $20.7(6.6)$ & $15.5(4.3)$ & 0.237 \\
b $^{*}$ & $32.0(3.5)$ & $28.2(2.6)$ & 0.040 \\
ITA $^{\circ}$ & $-11.5(6.3)$ & $-1.7(4.4)$ & 0.028 \\
MELASQoL & $70(68-70)$ & $32(22-41)$ & 0.027 \\
\hline
\end{tabular}

MASI Melasma Severity Index, ITA Individual Typology Angle, MELASQoL Melasma Quality of Life Scale

Standardised pictures, colorimetry (LED quasi-L"a"b*), skin biopsies (3 mm punch), MASI scores (range 0-48) and MelasQoL-PB questionnaire were taken at the inclusion visit (T0) and T45 [14-16]. The paraffin-embedded skin specimens were processed by haematoxylineosin, picrosirius-red, periodic acid Schiff and FontanaMasson staining.

The study was performed at Santa Casa de Misericórdia (Recife-PE, Brazil), from October to November 2016, and was approved by institutional board review (Comitê de Ética em Pesquisa da Faculdade de Medicina de Botucatu-Unesp).

Variables were compared between T0 and T45 by paired Student's t or Wilcoxon test if normality was not indicated by Shapiro-Wilk procedure [17].

Data was analysed at IBM-SPSS 24 and significance was set as two-sided $p<0.05$ [18].

Sample size was calculated to detect at least 30\% reduction of values of MASI scores between the visits, with an effect size (mean / standard deviation) of 1.1, alpha error of 0.05 and $80 \%$ of power [19].

\section{Results}

The age of the subjects varied from 34 to 46 years-old, Fitzpatrick' phototypes were III and IV, they reported 0 to 4 childbirths, daily time of direct sun exposure was 2 to $4 \mathrm{~h}$, age of melasma onset was 20 to 38 years and MASI ranged from 29 to 46.

All participants have treated melasma previously with triple combination and others hydroquinone-free bleaching agents, with relapse.

After two sessions of microneedling, improvement of melasma was perceived in all subjects (Figs. 1 and 2), in addition, there was a subjective report of overall facial skin smoothness and greater radiance by the participants.

Clinical, quality of life and colorimetric measures at T0 and T45 are presented at Table 1. A 70\% mean decrease in MASI, $13 \%$ increase in luminance $\left(\mathrm{L}^{*}\right)$ and $55 \%$ decrease in MELASQoL were noticeable.

Histologically (Figs. 3 and 4), all cases evidenced epithelium thickening, decrease in epithelial melanin pigmentation and densification of upper dermis collagen $(p=0.03)$. Basement membrane (Fig. 5) was damaged in melasma, and there are traces of basement membrane restoration after the treatment.

Patients were followed by 6 months under broadspectrum sunscreen and triple combination without relapse.

\section{Discussion}

This is the first preliminary study that investigated clinical, quality of life, colorimetric and histological improvement in facial melasma with the addition of microneedling to the classic treatment.

In a historical comparison with a Brazilian population $(n=50)$ submitted to a regimen of broad-spectrum sunscreen and triple combination for 8 weeks, there was a mean MELASQoL reduction from 44.4 to 24.3 (45\%) and a median MASI reduction from 13.1 to 3.2 (75\%) [20]. Nevertheless, that sample had a less severe melasma than our patients, there were no reports of previous treatment relapses and the intervention lasted $25 \%$ more than our study (60 vs. 45 days).

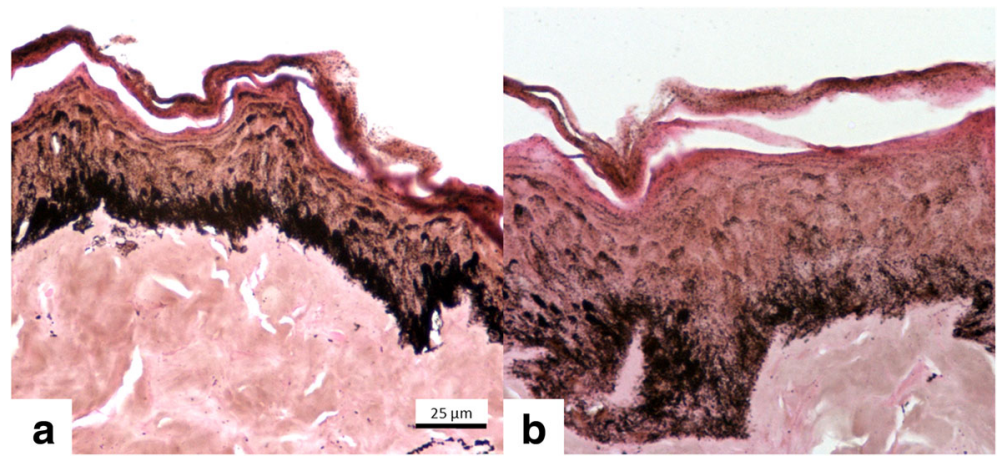

Fig. 3 Fontana-Masson staining. a Pre-treatment (T0). b Post-treatment (T45), evidencing acanthosis and decrease in melanin density and the size of granules 


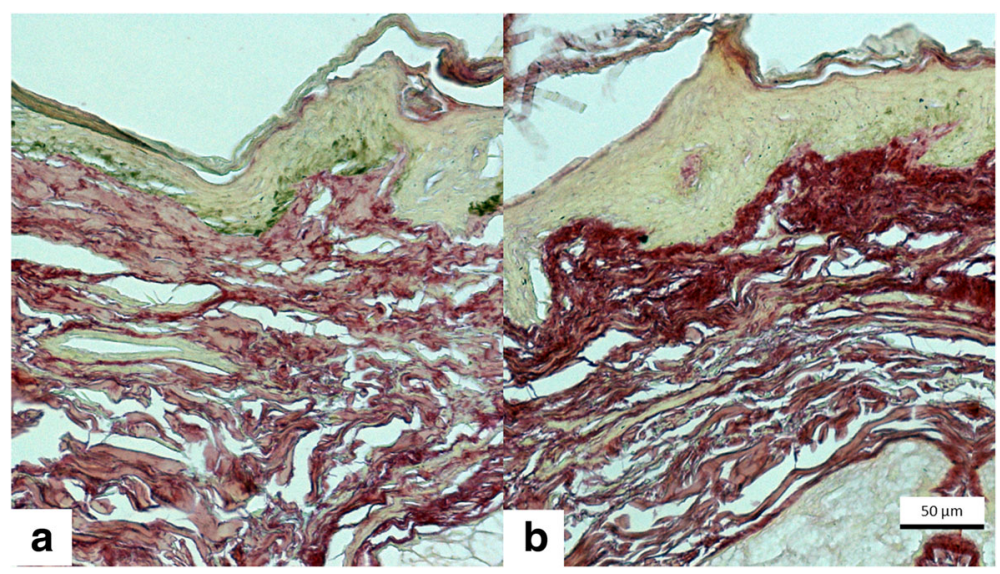

Fig. 4 Picrosirius red staining. a Pre-treatment (T0). b Post-treatment (T45), evidencing upper dermal dense collagen bundles

Beyond clinical and quality of life improvement, epidermal melanin reduction, basement membrane restoration and increase in upper dermal collagen were evidenced. Basal membrane is damaged in melasma, as there are solar elastosis and collagen fragmentation what lead to the hypothesis of great activity of metalloproteinases $[1-3,9]$ and in upper dermis and decrease in type I collagen synthesis $[8,21-23]$.

Microneedling is classically indicated in the treatment of striae distensae, acne scars and photoaging, but its indications are widening among dermatologists [24, 25]. Some patients with acne scars perceived improvement in their melasma after microneedling, what motivated us to study a specific treatment regimen for them [13]. As it promote fibroblast proliferation and upper dermal collagenesis, microneedling can restore upper dermal and basal membrane damage in melasma, disfavouring the contact of melanocytes with dermal released melanogenic stimuli as endothelin, stem cell factor and hepatocyte growth factor
[8, 22, 26, 27]. Additionally, a thickener epidermis can promote additional protection against UV damage.

In a previous histological study of triple association in melasma, the thickening of epidermis as well as upper dermal changes were not evidenced after 6 months of treatment [28]. This reinforces that the results we found in this preliminary study were induced by microneedling. Moreover, there is an increase in transepidermal drug delivery, for, at least, $72 \mathrm{~h}$ after the procedure. This can also increase the effect of triple association on the melanogenesis $[29,30]$.

Microneedling additional effects were suggested in a randomised controlled study with 60 patients comparing intradermal tranexamic acid versus its delivery by microneedling in facial melasma. There were respectively $36 \%$ and $44 \%$ improvement in MASI scores, moreover, $26 \%$ versus $41 \%$ of patients achieved $50 \%$ of MASI reduction [31]. Microneedling with vitamin $\mathrm{C}$ also resulted in a better clinical response followed

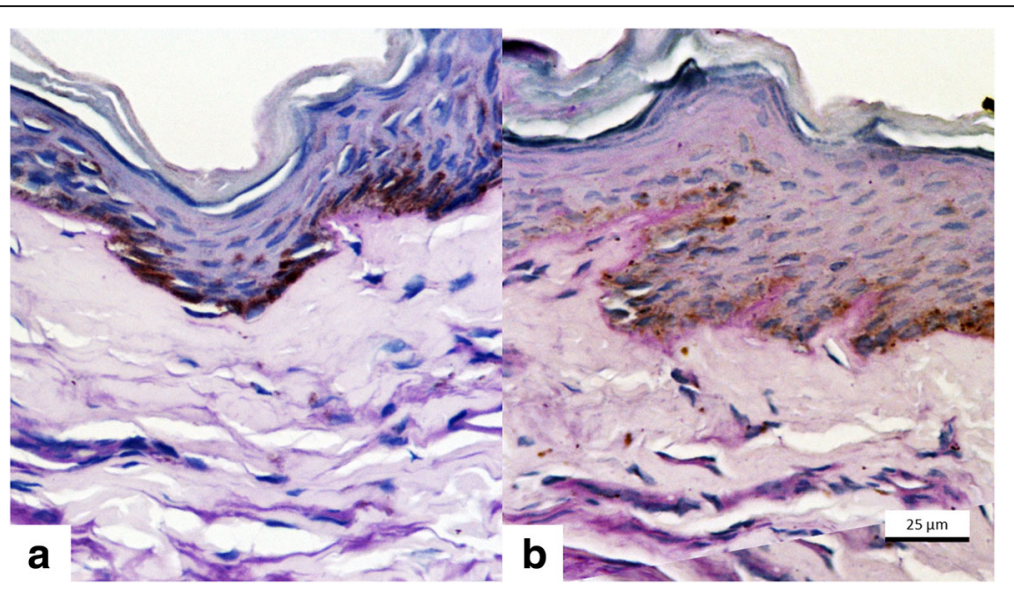

Fig. 5 Periodic acid Schiff staining. a Pre-treatment (TO). b Post-treatment (T45), evidencing previous severe damaging followed by traces of restoration in the basement membrane zone 
Q-switched Nd:Yag for facial melasma, in a split-face trial with 16 patients [32].

Gentle dermabrasion with dental motor roller provided persistent clearance of melasma in $97 \%$ of 410 patients in a Thai case series [33]. The mechanism of dermabrasion related improvement of melasma was also not understood, however, as well as microneedling it promotes upper dermal neocollagenesis.

This study has potential limitations. It was performed in a single centre in the Northeast of Brazil $\left(8^{\circ} 03^{\prime} 14^{\prime \prime} \mathrm{S}\right.$ and $\left.34^{\circ} 52^{\prime} 52^{\prime \prime} \mathrm{W}\right)$. Nevertheless, it is a sunny tropical city, what would disfavour the long-term remission observed at our follow up. The small sample size proposed in this pilot study also did not hamper we reach statistically significant results due to the consistency of the alterations induced by the treatment, as well as the main objective was to quantify clinical and histological alterations induced by microneedling in facial melasma. Finally, the addition of triple combination or the lack of a control group doesn't allow to assess the effect of isolated microneedling in the treatment, nonetheless, these histological findings were not reported after triple combination and they make sense in the reversion of melasma pathogenetic issues. Moreover, microneedling can facilitate drug delivery of bleaching actives $[28,34,35]$.

\section{Conclusions}

In addition to classic treatment (broad-spectrum sunscreen and triple combination), skin microneedling promoted clinical and histological improvement of recalcitrant facial melasma. Further randomised controlled studies are warranted to investigate treatment regimens of microneedling in order to maximize its efficacy, as long-term maintenance of the results.

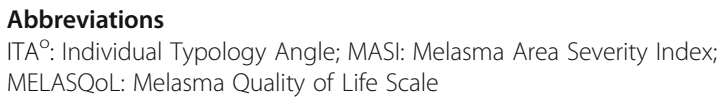

\section{Acknowledgements}

We thank the patients for their cooperation and all the technicians involved in this work.

We'd also like to acknowledge Dr. Amit Pandya and Raja Sivamani for the careful revision and pertinent suggestions to this manuscript.

\section{Funding}

No funding

\section{Availability of data and materials}

Data from this study are freely available and can be obtained by contacting the corresponding author.

\section{Authors' contributions}

EAL Data collection, final text composition and approval. MPP Data analysis, statistical analysis, final text composition and approval. MMAL Data collection, final text approval. HAM Data analysis, statistical analysis, final text composition and approval.

\section{Ethics approval and consent to participate}

This study has been approved by the Institutional Committee on Clinical Investigation (no 1.602.185).

Written informed consent was obtained from the patients to participate in this study and its publication and any accompanying images.

The study was performed at Santa Casa de Misericórdia (Recife-PE, Brazil), from October to November 2016, and was approved by institutional board review (Comitê de Ética em Pesquisa da Faculdade de Medicina de Botucatu-Unesp).

\section{Consent for publication}

Written informed consent was obtained from patients to participate in this study and its publication and any accompanying images.

\section{Competing interests}

The authors declare that they have no competing interests.

\section{Publisher's Note}

Springer Nature remains neutral with regard to jurisdictional claims in published maps and institutional affiliations.

\section{Author details}

'Santa Casa de Misericórdia, Praça Fleming, 35/1201 Jaqueira, Recife, PE 52050-180, Brazil. ${ }^{2}$ UNIFESP, São Paulo, SP, Brazil. ${ }^{3}$ Unesp Medical School, Botucatu, SP, Brazil. ${ }^{4}$ Departamento de Dermatologia, SN, Campus da Unesp, Botucatu, SP 18618-000, Brazil.

Received: 11 April 2017 Accepted: 21 November 2017

Published online: 28 November 2017

\section{References}

1. Handel AC, Miot LD, Miot HA. Melasma: a clinical and epidemiological review. An Bras Dermatol. 2014;89(5):771-82. doi:10.1590/abd1806-4841. 20143063

2. Sheth VM, Pandya AG. Melasma: a comprehensive update: part I. J Am Acad Dermatol. 2011;65(4):689-697. doi:doi:10.1016/j.jaad.2010.12.046.

3. D'Elia MP, Brandao MC, de Andrade Ramos BR, da Silva MG, Miot LD, Dos Santos SE, et al. African ancestry is associated with facial melasma in women: a cross-sectional study. BMC Med Genet. 2017;18(1):17. doi:10.1186/ s12881-017-0378-7.

4. Maranzatto CF, Miot HA, Miot LD, Meneguin S. Psychometrican analysis and dimensional structure of the Brazilian version of melasma quality of life scale (MELASQoL-BP). An Bras Dermatol. 2016;91(4):422-8. doi:10.1590/ abd1806-4841.20165014.

5. Ishiy PS, Silva LR, Penha MA, Handel AC, Miot HA. Skin diseases reported by workers from UNESP campus at Rubiao Jr, Botucatu-SP (Brazil). An Bras Dermatol 2014;89(3):529-531. doi:10.1590/abd1806-4841.20142875.

6. Miot LD, Miot HA, Polettini J, Silva MG, Marques ME. Morphologic changes and the expression of alpha-melanocyte stimulating hormone and melanocortin-1 receptor in melasma lesions: a comparative study. Am J Dermatopathol. 2010;32(7):676-82. doi:10.1097/DAD.0b013e3181cd4396.

7. Brianezi G, Handel AC, Schmitt JV, Miot LD, Miot HA. Changes in nuclear morphology and chromatin texture of basal keratinocytes in melasma. J Eur Acad Dermatol Venereol. 2015;29(4):809-12. doi:10.1111/jdv.12453.

8. Lee AY. Recent progress in melasma pathogenesis. Pigment Cell Melanoma Res. 2015;28(6):648-60. doi:10.1111/pcmr.12404.

9. Doddaballapur S. Microneedling with dermaroller. J Cutan Aesthet Surg. 2009;2(2):110-1. doi:10.4103/0974-2077.58529.

10. Lima Ede A, Lima Mde A, D. T. Microneedling: experimental study and classification of the resulting injury. Surg Cosm Dermatol 2013;5(2):110-114.

11. Hou A, Cohen B, Haimovic A, Elbuluk N. Microneedling: A Comprehensive Review. Dermatol Surg. 2017;43(3):321-39. doi:10.1097/DSS 0000000000000924.

12. Cohen BE, Elbuluk N. Microneedling in skin of color: a review of uses and efficacy. J Am Acad Dermatol. 2016;74(2):348-55. doi:10.1016/j.jaad. 2015.09.024

13. Lima Ede A. Microneedling in facial recalcitrant melasma: report of a series of 22 cases. An Bras Dermatol. 2015;90(6):919-21. doi:10.1590/abd1806-4841. 20154748. 
14. Takiwaki $\mathrm{H}$, Miyamoto $\mathrm{H}$, Ahsan K. A simple method to estimate CIE-L*a*b* values of the skin from its videomicroscopic image. Skin Res Technol. 1997; 3(1):42-4. doi:10.1111/j.1600-0846.1997.tb00158.x.

15. Pandya AG, Hynan LS, Bhore R, Riley FC, Guevara IL, Grimes P, et al. Reliability assessment and validation of the Melasma area and severity index (MASI) and a new modified MASI scoring method. J Am Acad Dermatol. 2011;64(1):78-83. doi:10.1016/j.jaad.2009.10.051.

16. Cestari TF, Balkrishann R, Weber MB, Prati C, Menegon DB, Mazzott NG, et al. Translation and cultural adaptation to Portuguese of a quality of life questionnaire for patients with melasma. Med Cutan Iber Lat Am. 2006;34: 270-4.

17. Miot HA. Assessing normality of data in clinical and experimental trials. J Vasc Bras. 2017;16(2):88-91. doi:10.1590/1677-5449.041117.

18. Norman GR, Streiner DL. Biostatistics: the bare essentials. 4th ed. Shelton: PMPH-USA; 2014.

19. Miot HA. Sample size in clinical and experimental trials. J Vasc Bras. 2011; 10(4):275-8. doi:10.1590/S1677-54492011000400001.

20. Cestari TF, Hexsel D, Viegas ML, Azulay L, Hassun K, Almeida AR, et al. Validation of a melasma quality of life questionnaire for Brazilian Portuguese language: the MelasQoL-BP study and improvement of QoL of melasma patients after triple combination therapy. Br J Dermatol. 2006;156(Suppl 1): 13-20. doi:10.1111/j.1365-2133.2006.07591.x.

21. Torres-Alvarez B, Mesa-Garza IG, Castanedo-Cazares JP, Fuentes-Ahumada C, Oros-Ovalle C, Navarrete-Solis J, et al. Histochemical and immunohistochemical study in melasma: evidence of damage in the basal membrane. Am J Dermatopathol. 2011;33(3):291-5. doi:10.1097/DAD. Ob013e3181ef2d45.

22. Byun JW, Park IS, Choi GS, Shin J. Role of fibroblast-derived factors in the pathogenesis of melasma. Clin Exp Dermatol. 2016:41(6):601-9. doi:10.1111/ ced. 12874.

23. Miot HA, Brianezi G. Morphometric analysis of dermal collagen by color clusters segmentation. An Bras Dermatol. 2010;85(3):361-4. doi:10.1590/ S0365-05962010000300010

24. Ramaut L, Hoeksema H, Pirayesh A, Stillaert F, Monstrey S. Microneedling: where do we stand now? A systematic review of the literature. J Plast Reconstr Aesthet Surg. 2017 (ahead of print). doi:S1748-6815(17)30250-4.

25. Alster TS, Graham PM. Microneedling: A Review and Practical Guide. Dermatol Surg. 2017 (ahead of print). doi:10.1097/DSS.0000000000001248.

26. Tamega Ade A, Miot HA, Moco NP, Silva MG, Marques ME, Miot LD. Gene and protein expression of oestrogen-beta and progesterone receptors in facial melasma and adjacent healthy skin in women. Int J Cosmet Sci. 2015; 37(2):222-8. https://doi.org/10.1111/ics.12186.

27. Lee DJ, Park KC, Ortonne JP, Kang HY. Pendulous melanocytes: a characteristic feature of melasma and how it may occur. Br J Dermatol. 2012;166(3):684-6. doi:10.1111/j.1365-2133.2011.10648.x.

28. Bhawan J, Grimes P, Pandya AG, Keady M, Byers HR, Guevara IL, et al. A histological examination for skin atrophy after 6 months of treatment with fluocinolone acetonide $0.01 \%$, hydroquinone $4 \%$, and tretinoin $0.05 \%$ cream. Am J Dermatopathol. 2009;31(8):794-8. https://doi.org/10.1097/DAD. Ob013e3181a9070d.

29. Lev-Tov H, Larsen L, Zackria R, Chahal H, Eisen DB, Sivamani RK Microneedle-assisted incubation during aminolaevulinic acid photodynamic therapy of actinic keratoses: a randomized controlled evaluator-blind trial. $\mathrm{Br}$ J Dermatol. 2017;176(2):543-5. doi:10.1111/bjd.15116.

30. Sivamani RK, Liepmann D, Maibach HI. Microneedles and transdermal applications. Expert Opin Drug Deliv. 2007;4(1):19-25. https://doi.org/10. 1517/17425247.4.1.19.

31. Budamakuntla L, Loganathan E, Suresh DH, Shanmugam S, Suryanarayan S, Dongare A, et al. A randomised, open-label, comparative study of Tranexamic acid microinjections and Tranexamic acid with microneedling in patients with Melasma. J Cutan Aesthet Surg. 2013;6(3):139-43. doi:10.4103/ 0974-2077.118403.

32. Ustuner P, Balevi A, Ozdemir M. A split-face, investigator-blinded comparative study on the efficacy and safety of Q-switched Nd:YAG laser plus microneedling with vitamin C versus Q-switched Nd:YAG laser for the treatment of recalcitrant melasma. J Cosmet Laser Ther. 2017:1-8. doi:10. 1080/14764172.2017.1342036

33. Kunachak S, Leelaudomlipi P, Wongwaisayawan S. Dermabrasion: a curative treatment for melasma. Aesthet Plast Surg. 2001;25(2):114-7. doi:10.1007/ s002660010107.
34. Bonati LM, Epstein GK, Strugar TL. Microneedling in all skin types: a review. J Drugs Dermatol. 2017;16(4):308-13.

35. Ornelas J, Foolad N, Shi V, Burney W, Sivamani RK. Effect of microneedle pretreatment on topical anesthesia: a randomized clinical trial. JAMA Dermatol. 2016;152(4):476-7. doi:10.1001/jamadermatol.2015.5544.

\section{Submit your next manuscript to BioMed Central and we will help you at every step:}

- We accept pre-submission inquiries

- Our selector tool helps you to find the most relevant journal

- We provide round the clock customer support

- Convenient online submission

- Thorough peer review

- Inclusion in PubMed and all major indexing services

- Maximum visibility for your research

Submit your manuscript at www.biomedcentral.com/submit
Biomed Central 